\title{
Field sketching - today and at the beginning of professional military mapping
}

\author{
Beata Medyńska-Gulij ${ }^{\text {a }}$ \\ ${ }^{a}$ Department of Cartography and Geomatics, Adam Mickiewicz University, Poznan, Poland, bmg@amu.edu.pl \\ * Corresponding author: Beata Medyńska-Gulij, bmg@amu.edu.pl
}

Keywords: field sketch, military mapping, topographic surveying, Europe, eighteenth century, GIS-GPS technology

\begin{abstract}
:
Field mapping is associated with topographic surveying and cataloguing elements of the natural environment on a topographic map on a scales ranging from 1:10.000 to 1: 50.000. The surveying instrument used for this purpose is mobile devices (tablet) with GIS software with an application making it possible to obtain topographic objects' coordinates on GPS-receiver. Mobile devices with GIS application open up the possibility of entering the attribute data into the database directly while in the field, displaying map bases in the form of WMS services, and connecting external measurement devices (e.g., laser rangefinder). The process of entering the attribute data in the field might be manual or automatic; the attribute values might be entered using the attribute libraries created specifically for this purpose in the office stage.
\end{abstract}

Military field mapping refers to the beginning of professional topographic surveying, i.e. military reconnaissance in eighteenth-century Europe. The map-drawing process started from the in-the-field graphic recording performed during observations, reconnaissance survey or plane-table drawing to the completed version - secret multi-sheet manuscript topographic maps. By the mid eighteenth-century rulers developed separate engineer corps (in France, Great Britain and in Prussia), quartermaster corps (in Austria, Denmark, and Norway, the Duchy of Savoy) and - exceptionally - an artillery corps (in the Austrian Netherlands) that specialized in field surveys and topographic mapping. The military corps functioned in this sense as educational institutions. Field survey and topography teachers emphasized the importance of acute observation, correct distance evaluation and sketching, both in rough sketchbooks and on plane table sheets. Because of the imperative of mapping rapidly to meet their monarchs' needs concerning prospective warfare tactics, officers able to map particular areas within a short time and performing by-eye reconnaissance enjoyed the highest status. Today, despite the use of topographic databases and remote sensing data, field mapping is still used to update of the topographic map content. Military topographers use different instruments and materials, e.g. a tablet with GIS-GPS mapping software; GPS receiver with compass; a prismatic compass; a digital or paper field sketchbook; printed fragments of the topographic map placed in surveyors folding frame with pencil; laser rangefinder or surveyor tape.

The aim of this study is to confront the importance of field sketching from the beginning of professional military mapping with the current ones. What universal values have remained until today in the sense of pencil and digital drawing? How valuable is the field reconnaissance skill? Is the art of field pencil drawing achievable with a pen on a digital drawing tablet? During the presentation, the author will invite you to discuss the following thesis: classical field sketching is an irreplaceable skill of the contemporary professional military mapping. Old unique manuscript cartographic drawings and today's digital field sketches will serve as arguments. 